\title{
Failure of Lactational Amenorrhea Method (LAM) in Yogyakarta
}

\author{
REZA BINTANG DARI JOHAN', MUFDLILAH² \\ ${ }^{1}$ Master of Midwifery Program, faculty of Health Sciences, 'Aisyiyah University of Yogyakarta, Indonesia \\ Coresponden author to Reza Bintang Dari Johanemail :Bintangbintangstarrbdj@gmail.com, mufdlilah.stikes@gmail.com
}

\begin{abstract}
Background: The lactational amenorrhea method (LAM) is modern contraceptives that rely on exclusive breastfeeding for six months without additional food or beverage. The mother is in a state of amenorrhea and delays arranging birth to a quality family.

Aim: The study aimed to determine the cause of the failure of LAM.

Method: Study design with the cross-sectional analytic survey, conducted on mothers who have babies 6-24 months of age as 79 respondents. The sampling technique using purposive sampling, data analysis chi-square, and logistic regression.

Result: This study showed parity $(\mathrm{OR}=4.861 ; 95 \% \mathrm{Cl}=0.991-23.852)$, education $(\mathrm{OR}=0.525 ; 95 \% \mathrm{Cl} 0.073-$ $3.758)$, work $(\mathrm{OR}=2.087 ; 95 \% \mathrm{Cl}=0.241-18.064)$, knowledge $(\mathrm{OR}=20.481 ; 95 \% \mathrm{Cl}=2.459-170.608)$, additional contraception other than $\operatorname{LAM}(\mathrm{OR}=2.894 ; 95 \% \mathrm{Cl}=0.365-22.965)$, menstruation before six months $(\mathrm{OR}=10.265 ; 95 \% \mathrm{Cl}=1.283-82.150)$, breast pump ( $\mathrm{OR}=1.843 ; 95 \% \mathrm{Cl}=0.189-17.990)$ and socioeconomic $(\mathrm{OR}=9.843 ; 95 \% \mathrm{Cl}=1.029-94.134)$.

Conclusion: In conclusion, all variables influenced LAM's failure, but the most influential was knowledge, menstruation before six months, and social-economic.

Keyword: LAM, breastfeeding, failure
\end{abstract}

\section{INTRODUCTION}

The population growth in Indonesia in 2017 was estimated at 26.9 million, an increase of 3.2 million from 258.7 million in 2016 [1]. Efforts of government to control population growth with the implementation of the family planning program [2]. The controlled population growth can realize quality family according to the vision of the family planning program, the target of implementing a family planning program is couples of reproductive age [3]. Indonesia has the highest number of women of reproductive age highest in Southeast Asia, 65 million, followed by the Vietnamese state of 25.3 million, Philippines 23 million, Thailand 17.9 million, Myanmar 14.1 million, Cambodia 4 million, Laos 1.6 million, and East Timor 0.3 million [4]. In 2017, the number of couples of reproductive age in Indonesia amounted to 23.6 million, which decreased from the previous year to 48 million people. However, the number of family planning acceptors in Indonesia increased to 37.3 million in 2017 compared to the previous year36.3 million people [5]. The number of family planning acceptors in 2017 in the Special Province of Yogyakarta amounted to 492.7 thousand, an increase from the previous year at 431.8 thousand. Contraceptive method most widely used injectable $45.40 \%$, $22.83 \%$ IUDs, pills $10.57 \%, 6.62 \%$ tubectomy, 6.21 implants\%, and a condom $5.21 \%$ [6]. There are two family planning methods: modern contraceptives consisting of sterilization, IUDs, implants, injections, pills, condoms, intravaginal/diaphragm, emergency contraception, and lactation amenorrhea methods and traditional contraceptive consisting of periodic abstinence and coitus interruptus [7]. Selection of contraception methods sometimes causing confusion and anxiety in the mother to choose the right contraceptive that can regulate or delay pregnancy; however, she does not want to use drugs or instruments. A mother can apply one contraception method with pretty good effectiveness, and the mother may choose the lactation amenorrhea method. Contraceptive LAM relies on exclusive breastfeeding without any additional food or beverages to meet three criteria. LAM has not obtained menses since giving birth, breastfeeding mothers fully ( $\geq 8$ times a day), and infants less than six months [8]. Research conducted by Kennedy effectiveness uses the lactation amenorrhea method at $98 \%$ to a six-month-old baby with a mother meet three criteria lactation amenorrhea methods [9]. Based on a consensus conference Bellagio results, the lactation amenorrhea method is effective for up to six months, even a year, if the mother has not menstruation and still breastfeed her baby [10].

The lactation amenorrhea method in Indonesia is still low, and it is measured from the low level of achievement of exclusive breastfeeding [11]. The level of achievement of exclusive breastfeeding is still low; it can be seen from the results of the implementation of the subsystem for recording and reporting of contraceptive services in Indonesia that showed the use of contraceptives in Indonesia, namely pills $13.6 \%$, IUD $3.9 \%$, injecting $31.9 \%$, condom $1.8 \%$, implant $3.3 \%$, tubectomy $3.2 \%$, vasectomy $0.2 \%, 1.3 \%$ periodic abstinence, coitus interruptus MAL $2.3 \%$ and $0.1 \%$. Indonesian people's knowledge about the lactation amenorrhea method ranks third in the bottom of the type of emergency contraception and diaphragm [12]. Knowledge about contraception lactation amenorrhea method in community-based aged $15-19$ years at $13 \%, 20-$ 24 years 20\%, 24\% 25-29 years, 27\% 30-34 years, 40-44 years and $45-49$ years $24 \%$ to $21 \%$, based on residence knowledge of lactation amenorrhea method is higher in urban areas amounted at $29.9 \%$ compared to the countryside which is $18 \%$. The educational level shows that knowledge about the methods of amenorrhea lactational highest in the level of education graduated from senior high school amounted to $37.4 \%$. In other words, the higher the education level, the higher the knowledge received [13]. Communities generally use hormonal contraception such as injections rather than traditional and modern contraceptives such as the lactation amenorrhea method 
because people believe injection contraception is a panacea [14].

The phenomenon that occurs in breastfeeding mothers is they breastfeed their babies exclusively, but in the fifth or six months before the postpartum mother experiences menstruation or pregnancy even though she does not use contraceptives in the form of instruments or drugs that are inserted into the body. This can be caused by several things such as the frequency of breastfeeding, contraception, parity, maternal age, maternal education, work, and socio-economic [15]. Research conducted by Valdés mentioned that breastfeeding, education, work, the social and cultural effects on the lactation amenorrhea method ( $p$-value $<0.05)$. The study aimed to determine the cause of the failure of LAM [16].

\section{METHOD}

A. Study Design: This study applied an analytical crosssectional survey to determine the cause of failure of the lactation amenorrhea method in postpartum mothers. This study had obtained a letter of ethics approval No. 05 / KEPUNISA / VII / 2017 from the Aisyiyah University ethics committee. The study lasted for three months in the area around 'AisyiyahMoyudan Clinic Sleman Yogyakarta.

B. Sampling: This study was conducted on all breastfeeding mothers who had children aged 6-24 months. The sampling technique applied purposive sampling with a sample of 79 respondents were following the criteria for inclusion such as mothers with babies aged 6-24 months, women with a history of exclusive breastfeeding, breastfeeding more than eight times a day, history of vaginal delivery, history of birth weight infants $\geq 2500$ grams, and a mother willing to become respondents. Meanwhile, the exclusion criteria included a history of congenital disabilities/abnormalities and mothers who had breast abnormalities, mothers infected with HIV-AIDS, and women who experienced mental health disorders.

C. Data collection and analysis: Data collection employed a questionnaire containing about causes of failure lactation amenorrhea method in breastfeeding mother. Researchers and research assistants did the first apperception, so there was no mistake of delivering information to the respondent when data were collected. The research assistant was a cadre in the local area that could allow researchers to approach the respondents. Researchers and research assistants handed out questionnaires directly to respondents with visit the patient's home. The researcher gave informed consent to respondents for availability participating in the study, and the researcher explained the objectives, procedures, and guaranteed confidentiality of the respondent's data. Data analysis used chi-square to see the relationship between variables and logistic regression to determine which variables most influence the lactation amenorrhea method's failure.

\section{RESULT}

Seventy-nine breastfeeding mothers participated in the study, and all respondents were Muslims; most of the maternal ages were $\geq 25$ years $(75 \%)$ and had more than one child (57\%). At the time of the study, $46.8 \%$ majority of recent mother's education was junior high schools, and
$74.7 \%$ of mothers worked at home as housewives or opened a business at home. Based on an economic standpoint, most mothers had considerable economic status $(79.7 \%)$, statistical results show $30.4 \%$ of breastfeeding mothers with a history of exclusive breastfeeding according to criteria lactation amenorrhea method and $69.6 \%$ did not fulfill the criteria because of several factors that lactation amenorrhea method failed in nursing mothers (Table 1$)$. socio-economic = district minimum wage

Table 1: Descriptive statistics

\begin{tabular}{|c|c|c|c|c|}
\hline Variable & Catagory & n $(\%$ & & $\begin{array}{l}\text { Standard } \\
\text { deviation }\end{array}$ \\
\hline \multirow{2}{*}{ Age } & $\geq 25$ years & 75 & $(94.9)$ & \multirow{2}{*}{0.221} \\
\hline & $<25$ years & 4 & $(5.10)$ & \\
\hline \multirow{2}{*}{ Religion } & Moslem & 79 & $(100)$ & \multirow{2}{*}{-0.000} \\
\hline & non moslem & 0 & $(0.0)$ & \\
\hline \multirow{2}{*}{ Parity } & Primipara & 34 & $(43.0)$ & \multirow{2}{*}{-0.498} \\
\hline & Multipara & 45 & $(57.0)$ & \\
\hline \multirow{4}{*}{ Education } & Junior High School & 12 & $(15.2)$ & \multirow{4}{*}{-1.095} \\
\hline & Senior High School & 37 & $(46.8)$ & \\
\hline & Diploma & 5 & $(6.30)$ & \\
\hline & College & 25 & $(31.6)$ & \\
\hline \multirow[b]{2}{*}{ Work } & Work at home & 59 & $(74.7)$ & \multirow[b]{2}{*}{0.438} \\
\hline & $\begin{array}{l}\text { Work outside the } \\
\text { home }\end{array}$ & 20 & $(25.3)$ & \\
\hline \multirow{2}{*}{$\begin{array}{l}\text { Socio- } \\
\text { economic* }\end{array}$} & Less & 16 & (20.3) & \multirow{2}{*}{-0.404} \\
\hline & Enough & 63 & $(79.7)$ & \\
\hline \multirow{2}{*}{$\begin{array}{l}\text { Lactation } \\
\text { amenorrhea } \\
\text { Method (LAM) }\end{array}$} & Yes & 24 & $(30.4)$ & \multirow[b]{2}{*}{0.463} \\
\hline & No & 55 & (69.6) & \\
\hline
\end{tabular}

Based on the test results for statistically bivariate showed parity $(\mathrm{OR}=4.238 ; 95 \% \quad \mathrm{Cl}=1.385-$ 12.969), work (OR $=5.351 ; 95 \% \mathrm{Cl}=1.132-25.295)$, knowledge $(\mathrm{OR}=7.808 ; 95 \% \mathrm{Cl}=2.085-29.241)$, additional contraception other than LAM $(O R=4.971 ; 95 \%$ $\mathrm{Cl}=1.657-14.911)$, menstruation before six months (OR $=5.920 ; 95 \% \mathrm{Cl} 2.061-17.004)$, breast pump $(\mathrm{OR}=5.351$; $95 \% \mathrm{Cl}=1.132-25.295)$, and social-economic (OR = $8.625 ; 95 \% \mathrm{Cl}=1.069-69.608)$ increases the risk of failure lactation amenorrhea method in exclusive breastfeeding mothers and statistically significant $(p<0.05)$, while education $(\mathrm{OR}=0.971 ; 95 \% \mathrm{Cl}=0.361-2.631)$ had no relationship or a low risk opportunity of failure (Table 2). The results of multivariate analysis of parity, education, work, knowledge, additional contraception other than LAM, menstruation before six months, breast pump, and socioeconomic influence the failure of lactation amenorrhea method in breastfeeding mothers and provided opportunities for LAM failure, but of the eight factors that most influenced failure LAM was knowledge of 20. 481 times the risk of LAM occurring, 10.265 times the risk of failure in women who experienced menstruation before six months, and the social economy at risk of 9,843 times (Table3).

\section{DISCUSSION}

The lactation amenorrhea method (LAM) is one of modern contraception based on a period of infertility to meet three 
criteria consisting of mothers exclusively breastfeeding until the baby is six months old, yet menstruation since birth, and infants aged $<6$ months [17]. The effectiveness of the lactation amenorrhea method can achieve $98 \%$ to prevent pregnancy [18]. The success of the lactation amenorrhea method depends on the mother's self [19]. Nevertheless, the use of these methods remains low despite exclusively breastfeeding mothers (Table 1). These findings are the same as in rural Turkey; the ratio of mothers who exclusively breastfeed is high, but the use of a low lactation amenorrhea method does not comply with the lactation amenorrhea method [20]. Researchers are analyzing the lactation amenorrhea method's failure based on parity, education, work, knowledge, contraception, LAM, menstruation before six months, pumping, and socioeconomic. The results showed a significant relationship between parity and failure of the lactation amenorrhea method ( $p$-value 0.013); similar to Hajian, and there was a relationship between parity and the return of menstruation to mothers who did exclusive breastfeeding [21] because the return of menstruation was a sign of a woman's fertility. According to Kazi, a woman has menstruation before six months postpartum, the effectiveness of LAM decreases [22].

Table 2: Failure of lactation amenorrhea method (LAM)

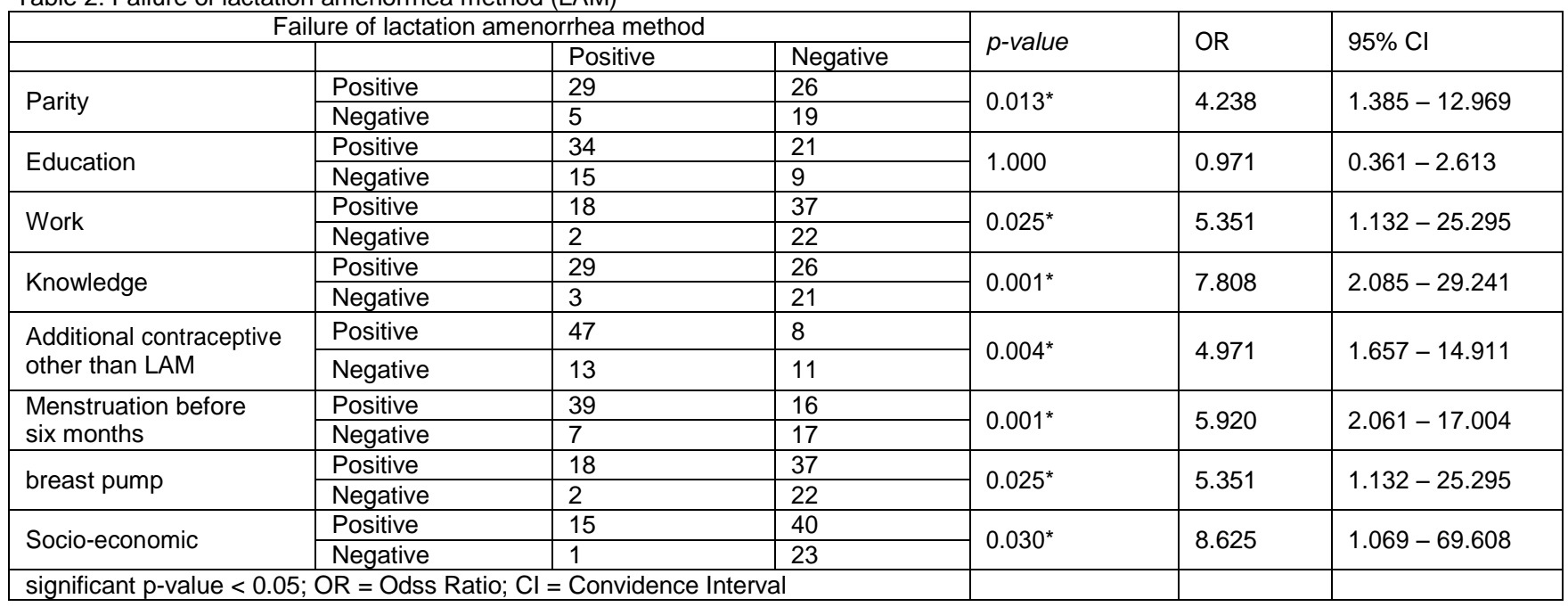

This study's other findings showed no significant relationship between education and the lactation amenorrhea method ( $p$-value 1.000). This research similar to research in the south-west Nigerian, the mother's education is not associated with lactation amenorrhea (Kuti et al., 2007). The education of mothers was mostly senior high school (table 1). Education at the senior high school level can be said as secondary education, meaning a mother has sufficient knowledge and can receive according to era development. According to Özsoy, women who have a high education tend not to use lactation amenorrhea as contraception because women tend to seek their information, experience from someone and follow trends [23]. Based on the work found $74.7 \%$ of mothers worked at home, and there was a significant relationship with the failure of the lactation amenorrhea method ( $p$-value 0.025 ). Based on the mother's knowledge of the lactational amenorrhea method of $59.5 \%$, the mother who fulfilled the lactational amenorrhea method's criteria was $69.9 \%$ (Table 1). The statistical results showed a relationship between knowledge and failure of maternal lactational amenorrhea method ( $p$-value 0.001). This finding is the same as that Ngum that mother knowledge about various types of contraception is excellent. However, contraceptive use is still low, especially in the lactational amenorrhea method, due to several inhibiting factors such as demographic factors (maternal age, education, parity), social, economic, and other contextual factors [24]. The mother only knows but does not understand the use of excellent and correct amenorrhea lactational methods. Good knowledge does not guarantee a person can practice correctly and adequately, and it can be influenced by themselves or others because the information obtained is less like information from health workers, so there needs to be an effort in the form of promotion from pregnancy to postpartum about the amenorrhea method lactational and how to use it. According to Özsoy, mothers were not given sufficient information about lactational amenorrhea, so most mothers wanted information and counseling about the effectiveness lactational amenorrhea method, including requirements, benefits, and work methods be done by health workers since pregnancy and childbirth [23]. This study is not the same as the research conducted by Mi. The mother's knowledge insufficient about the lactational amenorrhea method was followed by a low maternal knowledge about exclusive breastfeeding [25].

Researchers found that mothers breastfed their babies exclusively, but in the fourth or fifth month, the mother used additional contraception because the mother felt anxious about pregnancy. Contraception used by mothers is particular contraception of breastfeeding mothers who do not affect breast milk production because it only contains progestin. Some women experience menstruation at $60 \%$ (Table 1) due to the side effects of contraceptive use; according to Chao, mothers who use additional contraceptives such as the vaginal diaphragm and condoms while breastfeeding do not cause contraindications, so they are safe to use and do not affect 
fertility [26]. Research by Kazi women who had received menstruation again before six months postpartum should immediately continue with other contraceptive methods because of the possibility of a Higher pregnancy [22].
Furthermore, when a breastfeeding woman means the woman has practiced delaying fertility return, breastfeeding interferes with the ovulation and menstruation cycle [25].

Table 3: Multivariate Analysis

\begin{tabular}{|l|l|l|l|l|l|}
\hline Variable & $B$ & p-value & OR & $95 \% \mathrm{Cl}$ \\
\hline Parity & 1.581 & 0.051 & 4.861 & 0.991 & -23.852 \\
\hline Education & -643 & 0.521 & 0.525 & 0.073 & -3.758 \\
\hline Work & 0.736 & 0.504 & 2.087 & 0.241 & -18.064 \\
\hline Knowledge & 3.019 & $0.005^{*}$ & 20.481 & 2.459 & -170.608 \\
\hline Additional contraceptive other than LAM & 1.063 & 0.315 & 2.894 & 0.365 & -22.956 \\
\hline Menstruation before six months & 2.329 & $0.028^{*}$ & 10.265 & 1.283 & -82.150 \\
\hline Breast pump & 0.611 & 0.599 & 1.843 & 0.189 & -17.990 \\
\hline Socio economic & 2.287 & $0.047^{*}$ & 9.843 & 1.029 & -94.134 \\
\hline${ }^{*}$ Significant p-value $<0.05$ & \multicolumn{5}{l|}{} \\
\hline
\end{tabular}

Mothers who experience menstruation before the child is six months old, but the mother does not use contraception in drugs/instrument (33\%). This can be caused by other factors such as the mother not breastfeed her baby directly, researching Howie mothers who breastfeed their babies directly will experience menstruation again about 15 weeks after giving birth. In comparison, mothers who do not breastfeed their babies directly period of menstruation return about five weeks after giving birth because there is no direct pull on the mother's nipples [27]. According to Lewis, this can occur because mothers choose not to breastfeed their children, breastfeeding mothers but not exclusively, mothers use milk bottles at certain times, children sleep all night, children begin to be given solid food, and mothers start weaning their children [28]. According to King, breastfeeding is an effective contraceptive for six months after giving birth in exclusive breastfeeding conditions, continuously, and without using milk bottles [29].

According to Vekemans lactational amenorrhea method, utilizing the physiological processes when the baby suckles and still accounts for a significant proportion to separate pregnancies [30]. The physiological process that occurs when the baby sucks the breast will occur gonadotropin induction decreases hormone release, luteinizing hormone, and follicle-stimulating hormone, which results in amenorrhea, and mothers who do not breastfeed their babies or less breastfeeding frequency can accelerate the return of ovulation. According to Chao, women who breastfeed their children have a more extended period of amenorrhea and infertility than those who do not breastfeed their children [26]. The duration of the amenorrhea period is related to the frequency of breastfeeding, maternal age, parity, and nutrition. According to McNeilly, a hormone that plays a role in amenorrhea lactational is the hormone prolactin. Oxytocin, which is a hormone that is important in the process of spending breastfeeding, when the baby sucking the nipple to stimulate nerves sensory hypothalamus to secrete prolactin and stimulates the anterior pituitary to secrete the hormone prolactin, $\mathrm{FSH}$, and $\mathrm{LH}$ levels so low that it disrupts ovarian development and suppress ovulation due to the secretion of $\mathrm{GnRH}$ disrupted by the continuous baby sucking a pregnancy or menstruation does not occur [31]. Therefore, mothers who pump breast milk are more prone to pregnancy because there is no obstacle to the egg maturation by FSH and LH obtained from the baby's mouth suction, which will signal the mother's brain to inhibit hormone performance. According to King, the use of LAM will be useful if the distance to breastfeeding a baby is not more than 4 hours, feeding the baby at night, exclusive breastfeeding for the baby without additional food or drink, not pumping the baby's breast milk by hand or tool because it can reduce the mother's neuroendocrine response and increase the risk of ovulation and fertility even though the mother is breastfeeding her baby exclusive [29]. Other findings come from socio-economic; the socio-economic statistical results are related to the failure of the lactational amenorrhea method in nursing mothers with failure risk OR $=8.625$ (Table 2) with family income above the minimum or sufficient wage. According to Campbell et al. (2015), mothers who have high household incomes tend to be reluctant to use the lactational amenorrhea method and turn to other alternatives [32]. The lactational amenorrhea method is suitable for couples who do not want or are not interested in family planning, medication, or a calendar system. The lactation amenorrhea method is acceptable by certain religious authorities who oppose using contraceptives [30]. In this study, all respondents in Islamic religious studies (Table 1) agree that the lactationalamenroea method is an effective method for breastfeeding mothers and not against religion. These findings are similar to research in Turkey's lactational amenorrhea method acceptable to the Muslim community because this method does not require drugs or items placed in the body [33].

Based on multivariate analysis, it was found that overall it affected the failure of the lactational amenorrhea method. However, the most influential were knowledge, menstruation after six months, and socioeconomic ( $p$-value $<0.05$ ). Efforts can be made to support the success of the lactational amenorrhea method by introducing it from the beginning through communication, information, and education (IEC) during pregnancy to postpartum and a detailed description of the use of LAM contraception so that it can be practiced correctly and correctly. According to Türk, counseling services and education about the method of lactational amenorrhea need to be given to women so that contraception is more efficacious [33]. Besides, promotion needs to be done by offering women use lactational amenorrhea method. Research by Tommaselli recommends contraceptive methods for lactating 
amenorrhea to control birth with exclusive breastfeeding programs because this method is appropriate for controlling fertility in the postpartum period [34].

\section{CONCLUSION}

The lactational amenorrhea method's most influential failure is knowledge, menstruation before six months, and socio-economic. Lactational amenorrhea's failure can be minimized with mothers meeting three LAM criteria and mothers giving breast milk directly to the baby exclusively. Suppose the mother uses the lactational method of amenorrhea and menstruation six months after giving birth. In that case, the mother must use additional contraceptives that only contain progestin and the method of amenorrhealactational because it does not suppress breast milk production, and everyone has different hormone levels that affect the menstrual cycle if the mother wants to delay pregnancy. Besides, health workers need to provide more detailed information not only understanding the benefits of exclusive breastfeeding but also understanding the actual practice of using LAM and applying LAM provisions to understand breastfeeding as contraception.

\section{REFERENCES}

1. N. F. Moeloek, "Indonesia national health policy in the transition of disease burden and health insurance coverage," Med. J. Indones., vol. 26, no. 1, pp. 3-6, May 2017, doi: 10.13181/mji.v26i1.1975.

2. P. J. Gertler and J. W. Molyneaux, "How Economic Development and Family Planning Programs Combined to Reduce Indonesian Fertility," Demography, vol. 31, no. 1, p. 33, Feb. 1994, doi: 10.2307/2061907.

3. M. Cammack and T. B. Heaton, "Regional variation in acceptance of Indonesia's family planning program," Popul. Res. Policy Rev., vol. 20, no. 6, pp. 565-585, 2001, doi: https://doi.org/10.1023/A:1015659123964.

4. P. McDonald, "The Demography of Indonesia in Comparative Perspective," Bull. Indones. Econ. Stud., vol. 50, no. 1, pp. 29-52, Jan. 2014, doi: 10.1080/00074918.2014.896236.

5. O. B. Samosir, A. S. Kiting, and F. Aninditya, "Role of Information and Communication Technology and Women's Empowerment in Contraceptive Discontinuation in Indonesia," J. Prev. Med. Public Heal., vol. 53, no. 2, pp. 117-125, Mar. 2020, doi: 10.3961/jpmph.19.300.

6. D. K. Irawaty and H. Pratomo, "Spousal Communication on Family Planning and Contraceptive Adoption in Indonesia," Indian J. Public Heal. Res. Dev., vol. 10, no. 3, p. 372, 2019, doi: 10.5958/0976-5506.2019.00521.7.

7. J. Bongaarts, "The Impact of Family Planning Programs on Unmet Need and Demand for Contraception," Stud. Fam. Plann., vol. 45, no. 2, pp. 247-262, Jun. 2014, doi: 10.1111/j.1728-4465.2014.00387.x.

8. O. M. Shaaban, S. G. Hassen, S. A. Nour, M. A. Kames, and E. M. Yones, "Emergency contraceptive pills as a backup for lactational amenorrhea method (LAM) of contraception: a randomized controlled trial," Contraception, vol. 87, no. 3, pp. 363-369, Mar. 2013, doi: 10.1016/j.contraception.2012.07.013.

9. K. I. Kennedy, "Efficacy and Effectiveness of LAM," 2002, pp. 207-216.

10. R. . Short, M. . Renfree, G. Shaw, and P. . Lewis, "Contraceptive effects of extended lactational amenorrhoea: beyond the Bellagio Consensus," Lancet, vol. 337, no. 8743, pp. 715-717, Mar. 1991, doi: 10.1016/0140-6736(91)90288Z.
11. S. BECKER and S. AHMED, "Dynamics of contraceptive use and breastfeeding during the post-partum period in Peru and Indonesia," Popul. Stud. (NY)., vol. 55, no. 2, pp. 165-179, Jan. 2001, doi: 10.1080/00324720127688.

12. "The World Health Organization multinational study of breast-feeding and lactational amenorrhea. II. Factors associated with the length of amenorrhea," Fertil. Steril., vol. 70, no. 3, pp. 461-471, Sep. 1998, doi: 10.1016/S00150282(98)00191-5.

13. S. A. Wilopo, A. Setyawan, A. W. Pinandari, T. Prihyugiarto, F. Juliaan, and R. J. Magnani, "Levels, trends and correlates of unmet need for family planning among postpartum women in Indonesia: 2007-2015," BMC Womens. Health, vol. 17, no. 1, p. 120, Dec. 2017, doi: 10.1186/s12905-017-0476-x.

14. O. Lidegaard, E. Lokkegaard, A. L. Svendsen, and C. Agger, "Hormonal contraception and risk of venous thromboembolism: national follow-up study," BMJ, vol. 339, no. aug13 2, pp. b2890-b2890, Aug. 2009, doi: 10.1136/bmj.b2890.

15. I. B. Ahluwalia, "Why Do Women Stop Breastfeeding? Findings From the Pregnancy Risk Assessment and Monitoring System," Pediatrics, vol. 116, no. 6, pp. 14081412, Dec. 2005, doi: 10.1542/peds.2005-0013.

16. V. Valdés, M. H. Labbok, E. Pugin, and A. Perez, "The efficacy of the lactational amenorrhea method (LAM) among working women," Contraception, vol. 62, no. 5, pp. 217-219, Nov. 2000, doi: 10.1016/S0010-7824(00)00170-0.

17. M. H. Labbok, V. Hight-Laukaran, A. E. Peterson, V. Fletcher, H. von Hertzen, and P. F. A. Van Look, "Multicenter study of the Lactational Amenorrhea Method (LAM): I. Efficacy, duration, and implications for clinical application," Contraception, vol. 55, no. 6, pp. 327-336, Jun. 1997, doi: 10.1016/S0010-7824(97)00040-1.

18. R. A. Lawrence and R. M. Lawrence, "Reproductive Function During Lactation," in Breastfeeding, Elsevier, 2011, pp. 664688.

19. C. Van der Wijden, C., Manion, "Lactational amenorrhea method for family planning," Cochrane Database Syst. Rev. https://doi.org/10.1002/14651858.CD001329. pub2, 2015. .

20. E. Pirincci, R. Tasdemir, and A. Oguzoncul, "Knowledge of lactational amenorrhea as a contraceptive method among mothers of infants aged 0-6 months in a district, Eastern Turkey," Int. J. Community Med. Public Heal., pp. 13631370, 2016, doi: 10.18203/2394-6040.ijcmph20161601.

21. K. O. Hajian-Tilaki, "Factors Affecting the Pattern of Postpartum Amenorrhea," Ann. Saudi Med., vol. 22, no. 5-6, pp. 404-407, Sep. 2002, doi: 10.5144/0256-4947.2002.404.

22. A. Kazi, K. I. Kennedy, C. M. Visness, and T. Khan, "Effectiveness of the lactational amenorrhea method in pakistan*†," Fertil. Steril., vol. 64, no. 4, pp. 717-723, Oct. 1995, doi: 10.1016/S0015-0282(16)57845-5.

23. S. Özsoy, H. Aksu, N. Akdolun Balkaya, and G. Demirsoy Horta, "Knowledge and Opinions of Postpartum Mothers About the Lactational Amenorrhea Method: The Turkish Experience," Breastfeed. Med., vol. 13, no. 1, pp. 70-74, Jan. 2018, doi: 10.1089/bfm.2017.0046.

24. M. C. Ngum Chi Watts, P. Liamputtong, and M. Carolan, "Contraception knowledge and attitudes: truths and myths among African Australian teenage mothers in Greater Melbourne, Australia," J. Clin. Nurs., vol. 23, no. 15-16, pp. 2131-2141, Aug. 2014, doi: 10.1111/jocn.12335.

25. T. M. MI, "assess the knowledge on lactational amenorrhea as a contraceptive method among mothers of infants aged 06 months receiving mch services in a selected urban health centre at chennai.," Int. J. pharma Bio Sci., vol. 8, no. 1, Jan. 2017, doi: 10.22376/ijpbs.2017.8.1.b177-179.

26. S. Chao, "The Effect of Lactation on Ovulation and Fertility," Clin. Perinatol., vol. 14, no. 1, pp. 39-50, Mar. 1987, doi: 10.1016/S0095-5108(18)30780-2.

27. P. W. HOWIE, A. S. McNEILLY, M. J. HOUSTON, A. COOK, 
and H. BOYLE, "Fertility After Childbirth: Post-Partum Ovulation and Menstruation In Bottle and Breast Feeding Mothers," Clin. Endocrinol. (Oxf)., vol. 17, no. 4, pp. 323332, Oct. 1982, doi: 10.1111/j.1365-2265.1982.tb01597.x.

28. P. R. Lewis, J. B. Brown, M. B. Renfree, and R. V. Short, "The resumption of ovulation and menstruation in a wellnourished population of women breastfeeding for an extended period of time ${ }^{* *}$ Supported by National Health and Medical Research Council grant 840200, Canberra, Australian Capital Territory, Australia; L," Fertil. Steril., vol. 55, no. 3, pp. 529-536, Mar. 1991, doi: 10.1016/S00150282(16)54180-6.

29. J. King, "Contraception and Lactation," J. Midwifery Womens. Health, vol. 52, no. 6, pp. 614-620, Nov. 2007, doi: 10.1016/j.jmwh.2007.08.012.

30. M. Vekemans, "Postpartum contraception: The lactational amenorrhea method," Eur. J. Contracept. Reprod. Heal. Care, vol. 2, no. 2, pp. 105-111, Jan. 1997, doi:
10.3109/13625189709167463.

31. A. S. McNeilly, "Lactational control of reproduction," Reprod Fertil. Dev., vol. 13 , no. 8, p. 583,2001 , doi: 10.1071/RD01056.

32. O. M. R. Campbell et al., "Who, What, Where: an analysis of private sector family planning provision in 57 low- and middle-income countries," Trop. Med. Int. Heal., vol. 20, no. 12, pp. 1639-1656, Dec. 2015, doi: 10.1111/tmi.12597.

33. R. Türk, F. Terzioğlu, and K. Eroğlu, "The Use of Lactational Amenorrhea as A Method of Family Planning in Eastern Turkey and Influential Factors," J. Midwifery Womens. Health, vol. 55, no. 1, pp. e1-e7, Jan. 2010, doi: 10.1016/j.jmwh.2009.02.015.

34. G. A. Tommaselli, M. Guida, S. Palomba, M. Barbato, and C. Nappi, "Using complete breastfeeding and lactational amenorrhoea as birth spacing methods," Contraception, vol. 61, no. 4, pp. 253-257, Apr. 2000, doi: 10.1016/S00107824(00)00101-3. 